\title{
Contribution of New Sensors to Cartography
}

\author{
Carla Bernadete Madureira Cruz and Rafael Silva de Barros
}

Additional information is available at the end of the chapter

http://dx.doi.org/10.5772/48258

\section{Introduction}

Different cartographic representations are considered fundamental for the Geographic Science, whose characteristics are related, almost always, with the need for representation and analysis of spatially distributed phenomena. Therefore, it is fundamental that the cartographic bases are available, meeting the needs regarding the accuracy and updating, in different scales.

Generation and maintenance of these bases are considered as highly complex, considering all the planialtimetric information that they should contain, mainly in the case of a large country as Brazil, whose territory extends for about 8.5 million $\mathrm{km}^{2}$, with many areas of difficult access. Furthermore, there is a need for concern also with the thematic maps, whose origins depend on the cartographic bases themselves, which operate as spatial reference, besides other inputs originated normally from field surveys and remote sensing. The diversity of these maps is enormous, creating an immense variety of methods and specialists involved in their preparation.

With all this progress, cartography is presenting growing changes in the form of preparation and divulging of its products. The availability of new technologies, for acquisition, storage and dissemination of spatial data, made the use of maps and images increasingly popular, reaching not only government organizations and private companies, as habitual, but also individual users. On the other hand, this same technological progress has entailed a new context of methodological solutions, some of which presenting themselves as interesting alternatives for the process of maps generation, despite presenting also many future challenges. Changes to the way work is carried out are fundamental to attend viable solutions in ongoing applications, in the long-term, that also require a high level of quality, as those involving systematic cartography.

It is a fact that the consolidation of the Information Technology in practically all areas of knowledge, with the consequent cost reduction regarding software and hardware, was 
fundamental in this evolutionary process. Despite the intense and growing offer of technologies, the adsorption of the new methods and products, which were slowly converted from analog to digital, involves countless challenges, being slower than expected or desired. It should be highlighted also that the conversion requires the review of many concepts that need to be adapted to the new reality, as in the case of the sheets of charts in a certain scale in view of the challenge of preparation of continuous bases.

Therefore, an interesting new panorama is configured, which presents a diversity of uses with a growing demand for Geographic Information, associated, increasingly, with the use of Geographic Information Systems and products originated from Remote Sensing. The lack of control of individual actions, without the support of a detailed analysis on the real potentialities of the new products, can entail serious problems caused by inappropriate use of methods and/or inputs, making a wide discussion on the theme urgent, with establishment of a set of rules that supports such discussions.

Considering the images from Remote Sensing as growingly important inputs for cartography, it is emphasized that the diversity of new remote sensors, at different acquisition levels, and values of resolution and accuracy, allows to meet a variety of reference and thematic maps, in several scales.

\section{Considerations on remote sensing in cartography}

The use of remote sensing as important data source has been a reality for several decades, is ongoing and will probably be part of the everyday life of the population for many years to come - although most people are not even aware of it. The aerial level has supplied great volumes of data for cartography since the beginning of the 20th Century, whether in military or civilian applications, such as reference and thematic maps. In its evolution, it is also considered that the great revolution of the orbital phase has as main marker the launching of satellites focused on natural resources in the beginning of the 1970's.

In Brazil, practically all existent officially-based cartography was produced from aerial photos and, despite receiving satellite images from Landsat on the Cuiabá (MT) land station since 1973 in [1], only recently its use as input was adopted for the generation of reference cartographic bases.

The diffusion of micro-information technology also helped to increase the availability of free or low-cost images aimed at remote sensing image processing, contributing to a significant increase in the number and diversity of uses and applications. This growth occurred both in reference cartography as, mainly, in thematic cartography. Perhaps the climax of the dissemination occurred with the launching of Google Earth in 2005 in [2], making such products available for non-specialist users.

If on one hand such dissemination carted many benefits for most of the users (whether specialized or not), on the other hand it may contribute for the generation of products which do not present the expected, and often, required quality. Ignoring the phase of amazement which is common after launching products which in some way become object of consumerism, the 
products derived from remote sensing images may end up presenting a lower quality than desired, for, among other reasons, generating an expectation of intrinsic good quality. This may occur for being considered something modern, conveying the impression that the leading-edge technology is synonymous of - or is very near to present - guaranteed quality. In an opposite vision of the former, it is noted that there is a group of users who reveal suspicion or misbelief regarding the promised potentialities. Probably this occurs for different reasons, such as insufficient information, prejudice, or still, concerns with loss of jobs. Such resistances delay the renewal of methods and techniques, ending up to configure "pre-judgments" that end up making the performance of an analysis difficult, even in an emergency character, regarding their real efficacy. The results of our studies offer greater clarifications on products originated from different sensors, leading the reader to the need to break myths - pessimistic or optimistic regarding the use of remote sensing, mainly at orbital level for cartographic ends.

It is important also to consider that during recent years a lot of investment was carried out in new sensors, aiming to meet different applications. It is in place to state that we are being overrun by growing offers of novelties associated to many promises. The universe of remote sensors aimed at terrestrial studies is therefore very wide, involving products with several and variable spatial, radiometric, spectral and temporal resolutions. Such diversity allows the production of mappings with different detail and accuracy levels, of greater or minor complexity of legend and the possibility to follow up dynamic phenomena.

Another relevant consideration is the fact that many sensors allow also the extraction of 3-D data, also with different resolutions and accuracy levels. One fundamental mark in this area is undoubtedly SRTM (Shuttle Radar Topography Mission), which despite not having been the pioneer, is the most encompassing and popular Digital Elevation Model (DEM) available worldwide. Consequently, there is a growing need to study the quality of the altimetry obtained from such sensors, and also an assessment of how much the implemented advances in the data acquisition process can influence the results, as for instance the alongtrack stereoscopy (images acquired during satellite orbit) and interferometry.

A differentiation between DEM and Digital Terrain Models (DTM) can be useful, because often this is one of the arguments against the use of orbital images for the generation of terrain representations. In a simplified way, it will be assumed that the DEMs represent the land surface added by any existent objects on it and which influence the value of the pixel reflectance. In other words if there are trees and constructions, the surface represented refers to the top of them. The DTMs on the other hand, represent the actual ground surface.

Despite so many investments in orbital sensors, the airborne surveys still offer greater accuracy for their products. It is emphasized also that there are some benefits of the active sensors in relation to passive sensors, as the case of the interferometer radar and LIDAR (LIght Detection And Ranging), which are not subject to atmospheric interferences and allow extraction of DEMs and DTMs - depending on the band for radar and the density of points for LIDAR.

In the case of new methodologies for generation of DEM/DTM to meet the expectations, reaching greater detail scales, an important step was taken in the sense of generating data with a good cost/benefit relation, mainly regarding time reduction, if compared with 
conventional methodologies. In such case the topographic features can be obtained for the most extensive areas of our country, meeting a demand of great part of the studies and activities related to topographic representation.

The interest in investigation on altimetry spawned by orbital products arises from the fact that planimetry has already been studied, both in meeting thematic and reference cartography. Besides the need of studies related to altimetry, this category has been raising growing uses and interest. For some examples of the use of altimetry in studies related to thematic cartography, see [3-7]. To exemplify applications related to reference cartography, see [8-12].

In the case of Brazil, cartography still presents serious problems related to the updating of the existent bases and availability of appropriate scales for the most different studies in [13], especially in scales with greater detail of systematic mapping, as for instance, 1:100,000 and 1:50,000 which are very useful in environmental and urban studies.

\section{Accuracy of the planimetric and altimetric representations: Case studies}

A proposal to minimize the problems presented - rejection of indiscriminate utilization - is the creation of a culture for assessment of the quality and validation of the generated products. This way, maybe, we come closer to know what is real. There is a norm called Cartographic Accuracy Standard (PEC, in Portuguese - [14]) to classify cartographic products. However its application has always been limited. PEC was created in the 1980's, when cartography was still in the analog phase. With the change to digital cartography, new approaches are required regarding assessment of planimetric, and especially altimetric accuracy. In [15] it is possible to see a discussion on the use of PEC in present days, calling attention for the need of changes and inclusion of statistical tests, not foreseen in the present norm.

PEC makes reference to the assessment of final products through the use of control points for checking how much the points located on a map deviate from their homologous located on the ground. For each quality class - which can also be understood as accuracy - a standard value is specified to be reached by at least $90 \%$ of the points, as well as a limit value for the Mean Square Error - understood as synonymous of standard deviation. Said simply, this norm applies both for planimetric as altimetric assessments.

Notwithstanding all our concerns regarding the quantity and quality of information that can be extracted from remote sensing products, the volume of products originated from new sensors grows every day and the demand for investigation regarding accuracy of its geometry, considering what is established in the PEC, is still very large. As suggested above, probably this is explained by some factors such as insufficient knowledge of such need or the lack of norms or standards for other types of assessments that may be used as reference.

ESPAÇO Remote Sensing and Environmental Studies Laboratory of the Department of Geography of the Federal University of Rio de Janeiro (UFRJ) has a research line aimed at assessment regarding the geometry of several products originated from remote sensing since 
2004. As these products are increasingly used in the production of cartographic data, a brief summary of the results obtained in the case studies carried out by members of the research group during that period is presented. To facilitate the search, the results were grouped in three different Classes of scales: 1) scales over 1:25,000; 2) 1:25,000; 3) 1:50,000 or less.

All assessments of the planimetric and/or altimetric accuracies used as reference what is provided in the PEC; which establishes that $90 \%$ of the points tested should present errors below certain tolerance values and the total set of points cannot surpass a standard deviation limit. These thresholds are determined for each quality class, which varies from A (higher accuracy) to C (less accuracy). Table 1 below presents the specific thresholds for the planimetric and altimetric accuracies.

\begin{tabular}{|c|c|c|c|c|}
\cline { 2 - 5 } \multicolumn{1}{c|}{} & \multicolumn{2}{c|}{ Planimetry } & \multicolumn{2}{c|}{ Altimetry } \\
\hline Class & Tol. $(\mathrm{mm})$ & SD $(\mathrm{mm})$ & Tol. & SD \\
\hline A & 0.5 & 0.3 & $1 / 2$ Eq. & $1 / 3$ Eq. \\
\hline B & 0.8 & 0.5 & $3 / 5$ Eq. & $2 / 5$ Eq. \\
\hline C & 1.0 & 0.6 & $3 / 4$ Eq. & $1 / 2$ Eq. \\
\hline
\end{tabular}

Tol.: Tolerance; SD: Standard Deviation; Eq.: Altimetry difference between contour lines (Contour Interval)

Table 1. Limits of planimetric and altimetric tolerances indicated by the PEC

It is emphasized that, despite the PEC not being indicated for assessment of digital products and inputs used in the cartographic production process, this standard was adopted in the studies here performed for being the only existent official norm in Brazil for assessment of cartographic products. The use of the PEC serves mainly, to have a national reference for comparison of the planialtimetric accuracy of cartographic products.

It is stressed also that the assessments refer only to the geometry related accuracy. Most of the assessed products - if not all of them - present information extraction capacity for lower scales than those scales for which its geometry is compatible.

All assessments should be treated as case studies, in view that they refer to the assessment of a unique scene/acquisition for each product, with the possibility of the existence of different results for other study areas. The assessment of planimetric accuracy was always carried out using the generated orthoimage, while the altimetric accuracy evaluation was made directly on the DEM and/or DTM obtained from the sensor images.

The results for each group are presented below, describing the types of evaluated sensors, their common features, besides the results themselves found in the case studies.

\section{Scales greater than 1:25,000}

\subsection{IKONOS 2: Planialtimetric evaluation of the orthoimage and DEM}

Ikonos 2 satellite was launched in 1999, being the first one with high-definition available on the market, with a spatial resolution of $1 \mathrm{~m}$ for the panchromatic band and 
$4 \mathrm{~m}$ for the multispectral bands (blue, green, red and near infrared), and radiometric resolution of 11 bits. Another novelty offered was the acquisition of the stereo pair in the same orbit.

The Ikonos product used in this assessment comprises four scenes (two stereoscopic pairs), in the GeoOrtho Kit mode (with RPCs - Rational Polynomial Coefficients), acquired on April 11, 2009. The assessment only used the panchromatic band.

Study area is located near the border between São Sebastião and Caraguatatuba, both municipalities of the northern coastline of the state of São Paulo. This area is inserted in the Serra do Mar (Sea Mountain Range), which in this area presents height differences of up to $800 \mathrm{~m}$, with vegetable cover of the tropical forest type.

Scenes referring to the panchromatic band were modeled in Orthoengine 10.2, of PCI Geomatics, making use of RPCs and seven GCPs (Ground Control Points). The orthoimage was generated with the nominal resolution of the raw scene $(1 \mathrm{~m})$ and the DEM was generated with resampling, taking the pixel to $2 \mathrm{~m}$. For assessment, 32 points were used, all surveyed with GNSS, through relative static positioning, with single frequency (L1) trackers.

Regarding planimetric accuracy, the results indicated the orthoimage as class $C$ for 1:2,000 scale, having in view that $96.9 \%$ of the points used in the assessment presented errors of up to $2 \mathrm{~m}$ and Standard Deviation (SD) of $0.5 \mathrm{~m}$, demonstrating a very low internal error.

Regarding altimetric accuracy, the generated DEM from the panchromatic band could be fitted in class C for 1:10,000 scale, because $91.2 \%$ of the points used presented errors of up to $3.75 \mathrm{~m}$ and SD of $2.0 \mathrm{~m}$.

\subsection{GEOEYE 1: Planialtimetric assessment of orthoimage and DEM}

Images of the Geoeye satellite are among those with highest spatial resolution available at present. The acquisition of stereoscopic pairs is also made along the same orbit. The sensor presents a panchromatic band of $0.5 \mathrm{~m}$ spatial resolution and multispectral bands (blue, green, red and near infrared) of $2.0 \mathrm{~m}$ spatial resolution, and radiometric resolution of 11 bits. The stereoscopic pairs used in this assessment where acquired with RPCs.

Study area comprises the Ilha Grande Island, located in the municipality of Angra dos Reis, in the south of the state of Rio de Janeiro. The prevailing relief is mountainous, with a vegetable cover of the tropical forest type, presenting height differences of up to $1,000 \mathrm{~m}$.

The stereoscopic Geoeye pair, acquired on March 24, 2011, was modeled by Orthoengine 10.2 of PCI Geomatics, using RPCs, 6 GCP and seven Tie Points. For assessment 24 points were used, all of which had their coordinates determined by relative static positioning, using 2-frequency (L1L2) GNSS trackers.

The orthoimage, generated with nominal resolution of $0,5 \mathrm{~m}$, presented planimetric accuracy compatible with the specification, according to PEC, for class B for 1:2,000 scale, since $90 \%$ of the points used in the assessment presented errors of up to $1 \mathrm{~m}$ and SD of 0.3 
$\mathrm{m}$. The DEM was generated with resampling, taking the pixel to $2 \mathrm{~m}$. The altimetric accuracy was consistent with Class $\mathbf{C}$ for $1: 10,000$ scale, since $90 \%$ of points used in the evaluation showed errors of up to 3.2 meters and SD of 2.3 meters.

\subsection{LIDAR: Planialtimetric assessment of orthoimage, DTM \& DEM}

The LIDAR (LIght Detection And Ranging) used in this assessment comprised not only DTM and DEM generated by LIDAR proper, but also orthophotos generated from photos acquired during the survey with a non-metric camera. The point cloud was not assessed, since the ESPAÇO laboratory only received the models generated and the orthophotos, which presented a $25 \mathrm{~cm}(10 ")$ resolution. The LIDAR sensor used was Optech ALTM 2050 (Airborne Laser Terrain Mapper), configured for a point density equivalent to one point at each $80 \mathrm{~cm}$. The airplane used, besides outfitted with a double frequency GNSS tracker, also used an IMU (Inertial Measurement Unit), responsible for recording the airplane altitude variations. The great interest in LIDAR, besides the good accuracy expected and speed in data processing, is the possibility of penetration into the vegetation, due to its high point density.

Thirty-six (36) evaluation points were used, with 29 identified in the orthophotos. All points had their coordinates determined by relative static positioning, with single frequency GNSS trackers.

Study area is located near the border between São Sebastião and Caraguatatuba, municipalities of the northern coastline of the state of São Paulo. This area is inserted in the Serra do Mar Range, which in this area presents height differences of up to $800 \mathrm{~m}$, with vegetable cover of the tropical forest type.

Orthoimages showed excellent planimetric accuracy, presenting a CE90 (Circular Error at $90 \%$ ) of $0.86 \mathrm{~m}$ and SD of $0.3 \mathrm{~m}$. With these values it is possible to say that it presented an accuracy compatible with class A for 1:2,000 scale because, besides the SD being below the limit for this scale, $93.1 \%$ of the 29 points used in the assessment were below the limit for this scale.

The DEM presented good altimetric accuracy, with a LE90 (Linear Error at 90\%) of 1.33 meters and SD of $0.73 \mathrm{~m}$, presenting itself compatible with the indication by PEC for class C for I:5,000 scale, assuming that the contour lines present $2 \mathrm{~m}$ of contour interval. A total of $33(91.7 \%)$ of the 36 points used in the assessment presented errors below specification $(1.5 \mathrm{~m})$.

The DTM presented an even better performance, presenting a LE 90 of $0.58 \mathrm{~m}$ and SD of 0.4 $\mathrm{m}$, which would make it compatible with the indication for a class B for I:2,000 scale, since $91.6 \%$ of the points used in the assessment presented errors up to the specified value $(0.6 \mathrm{~m})$ for this class.

The results obtained in the assessment of the LIDAR data were very good, but it was not expected that the altimetric accuracy of the DEM would be lower than the DTM accuracy. It 
is possible that there was a better treatment of the point cloud during data processing regarding the last return (responsible for DTM generation) in detriment of the data of the first return (that lead to the DEM generation).

\section{5. $1: 25,000$ scale}

\subsection{Cartosat-1: Planialtimetric assessment of orthoimage and DEM}

The Cartosat-1 satellite - or IRS P5 - is aimed for cartographic applications, especially reference applications, for having only a panchromatic band, but with 2 different acquisition angles in the same passage. Its radiometric resolution is of 10 bits.

The stereoscopic pair analyzed covers the surroundings of São Sebastião, the same area mentioned before.

The stereoscopic pair, acquired on May 23, 2009, was processed with Orthoengine 10.2, by PCI Geomatics, using RPCs, with 7 GCPs and 8 Tie Points. The orthoimage was generated with nominal resolution equal to the rated resolution $(2.5 \mathrm{~m})$ and the DEM was resampled for $10 \mathrm{~m}$. For assessment 30 points were used. All points were surveyed with GNSS equipment, with relative static positioning, with single frequency trackers.

The results were quite satisfactory, with the orthoimage reaching a class B for 1:10,000 scale, with $93.3 \%$ of the points presenting errors of up to $8 \mathrm{~m}$ and SD of $2.7 \mathrm{~m}$. Altimetric accuracy was compatible with the specification for a class A for 1:25,000 scale, since $94.1 \%$ of the assessment points presented errors of up to $5 \mathrm{~m}$ and SD of $2.8 \mathrm{~m}$.

\subsection{ALOS/PRISM: Planialtimetric assessment of orthoimage and DEM}

PRISM sensor onboard ALOS ${ }^{1}$ satellite acquired data only into panchromatic band, but with telescopes in three different incidence angles (Backward, Nadir and Forward), with a spatial resolution of $2.5 \mathrm{~m}$. Operating in this mode, called Triplet, it presented optimal conditions for DEM generation, considering that different view combinations could be used, according to relief variation or any other needs.

PRISM data, likewise those from AVNIR2 were distributed by IBGE (Brazilian Institute for Geography and Statistics) to noncommercial users for much lower prices than those practiced by the market for compatible products. It explains the interest in such data and the need for assessments.

The results presented here referred to the assessment report of PRISM data in [16] and the work presented by some IBGE employees in [17], who assessed the accuracy of the geometry from a PRISM Triplet acquired with a 1B2R processing level covering the surroundings of the municipality of Itaguaí, in Rio de Janeiro.

The data was processed by Orthoengine 10.1, of PCI, without RPCs, but using 7 GCPs and 11 Tie Points. The orthoimage was generated with a Nadir view of $2.5 \mathrm{~m}$ and the DEM was

${ }^{1}$ ALOS satellite experienced trouble in April 2011 and was disconnected in May of the same year. 
generated using the backward and forward views, resampled for $10 \mathrm{~m}$. For assessment ends, 88 points were used, whose coordinates were determined by relative static positioning, making use of double frequency GNSS trackers.

The authors initially made a planimetric accuracy assessment of an orthoimage generated with 7 GCPs and SRTMDEM. The results showed that, even using a SRTM DEM, with $90 \mathrm{~m}$ pixels, the orthoimage would be compatible with an indication for class A for 1:25,000 scale, since the 40 points used in this initial assessment presented errors of up to $9.6 \mathrm{~m}$, with SD of $2.1 \mathrm{~m}$. Subsequently, the assessment was complemented using a DEM generated from the Triplet PRISM data. The results were also satisfactory and similar to those obtained with Cartosat1. The orthoimage presented planimetric accuracy compatible with class $\mathbf{B}$ for 1:10,000 scale, despite the authors' mentioning only attendance to scale 1 to 25,000 (which was the target of the assessment), since all points presented errors up to $7.9 \mathrm{~m}$ and SD of 1.9 $\mathrm{m}$. The altimetric accuracy of the DEM was compatible with class A for 1:25,000 scale since $92 \%$ of the assessment points presented errors of up to $5 \mathrm{~m}$ and SD of $2.3 \mathrm{~m}$.

\section{Scales 1:50,000 or less}

\subsection{SRTM DEM: Altimetric assessment}

The DEMs generated from the data of this mission by NGA (National Geospatial Intelligence Agency), NASA (National Aeronautics and Space Administration), have been widely used in Brazil - as well as in other countries - for being free, of good quality and with almost global coverage. Since its first divulging, in version 1, the immense potential for its use was perceived, mainly in locations without altimetric data of better quality and coverage in digital media. In function of the different versions available, four of them were chosen to be evaluated:

- Version 1: Original DEM with pixel resampled to $90 \mathrm{~m}$, with negative values and many areas without data, distributed by NASA. Additional information may be obtained on the site http://www2.jpl.nasa.gov/srtm/;

- Version 2: Includes additions made to version 1, with delimitation of a coastline, elimination of negative values and reduction of areas without data, also distributed by NASA. Additional information may be obtained on the site http://www2.jpl.nasa.gov/ $\operatorname{srtm} /$;

- Version 4: Derived from version 1, maintains a $90 \mathrm{~m}$ pixel, as well as some negative values, but completes the areas without data. This version is divulged by CGIAR (Consortium of International Agricultural Research Centers). Additional information may be obtained at: http://srtm.csi.cgiar.org/SELECTION/inputCoord.asp;

- Topodata: This version was generated and distributed by INPE in [18], with reprocessing of version 1 data for the Brazilian territory, resampling the pixel for $30 \mathrm{~m}$ by kriging. Additional information can be obtained at: http://www.dsr.inpe.br/ topodata/index.php;

The assessment was made in the same way for the four versions, with small variation in the number of assessment points (between 90 and 92 points, depending on the DEM version) - 
all surveyed with GNSS, through relative static positioning, with single frequency trackers in function of the variation of the pixel size and the coastline. The study area corresponds to part of the municipality of São Sebastião on the north coast of the state of São Paulo, in southeast Brazil.

Table 2 presents a summary of the assessment results from the SRTM DEM in the four versions. In it, the number of assessment points used in each product are shown, as well as the percentages of points with errors up to the limit for a class $C$ for scale 1:50,000 (15 m) and class A for scale 1:100,000 (25 m) as well as the Standard Deviation (SD) of each set of points used in the assessment for each DEM SRTM version.

\begin{tabular}{|c|c|c|c|c|}
\hline $\begin{array}{c}\text { DEM } \\
\text { SRTM }\end{array}$ & $\begin{array}{c}\text { Assessment } \\
\text { Points }\end{array}$ & $\begin{array}{c}\text { Class C } \\
\mathbf{1 : 5 0 , 0 0 0}\end{array}$ & $\begin{array}{c}\text { Class A } \\
\mathbf{1 : 1 0 0 , 0 0 0}\end{array}$ & $\begin{array}{c}\text { SD } \\
(\mathbf{m})\end{array}$ \\
\hline Version $\mathbf{1}$ & 90 & $91.10 \%$ & $100 \%$ & 6.82 \\
\hline Version $\mathbf{2}$ & 91 & $90.50 \%$ & $100 \%$ & 6.85 \\
\hline Version 4 & 91 & $90.10 \%$ & $100 \%$ & 6.84 \\
\hline TOPODATA & 92 & $83.30 \%$ & $93.40 \%$ & 10.38 \\
\hline
\end{tabular}

Table 2. Summary of assessments of the 4 versions of DEM SRTM

From the results presented in table 2 one perceives that versions 1, 2 and 4 have very similar performances and present altimetric accuracy very near to the limits indicated for class $\mathbf{C}$ of scale 1:50,000. Only Topodata is indicated only for class A of scale 1:100,000. As the main objective of Topodata is to obtain a better detailing of the morphometric information derived from SRTM DEM, a small loss of accuracy is tolerated in favor to gain better detailing of the morphometric representation. Additionally, the goal and SD observed should be emphasized, mainly in versions 1, 2 and 4, showing that the DEM SRTM presents homogeneity and consistency in results.

\subsection{ASTER/VNIR: Planialtimetric assessment of the orthoimage and DEM}

ASTER images (Advanced Spaceborn Emission and Reflection Radiometer), onboard Earth satellite, are very interesting for being of low-cost and providing good spectral resolution, besides allowing the generation of DEMs from the stereoscopic pair of the VNIR (Visible and Near Infrared) sensor. This sensor provides a spatial resolution of $15 \mathrm{~m}$, counting with the green, red and near infrared bands (the latter being acquired with two different incidence angles in a same satellite passage). Due to these features, those images can be useful both for thematic as for reference cartography.

Study area again was the vicinities of the municipality of São Sebastião. An assessment was carried out based on the results made from the images and DEMs generated according to two different approaches:

- With Orthoengine 10.2 by PCI Geomatics based on 2 scenes (same date) acquired September 19, 2008, with processing level L1A, making use of 12 control points and 9 Tie Points per scene. 
- With ENVI / ASTER MDT: using the same scenes (same date), with the same processing level and control points; and using the same scene, however with L1B processing level and without control points.

The orthoimages and DEMs generated for assessment had the same resolution as raw data: $15 \mathrm{~m}$, despite having carried out tests of the DEM with pixels resampled up to $60 \mathrm{~m}$, without perceiving significant difference.

There was no disagreement between the results obtained for planimetry, placing the VNIR orthoimages in class A for 1:50,000 scale, with $92.7 \%$ of the 41 assessment points presenting errors of up to $40 \mathrm{~m}$, with a standard deviation of $11.6 \mathrm{~m}$.

In the case of altimetry, however, results were different depending on the approach used in DEM generation. Using Orthoengine, the worst results were obtained, since DEM meets the specifications for class A for 1:100,00 scale, with $94.2 \%$ of the assessment points presenting errors of up to $25 \mathrm{~m}$, with a standard deviation of $10.5 \mathrm{~m}$. When using the ENVI /ASTERDTM, with the same scenes, processing level and same 12 control points, the result changes to a class $C$ for $1: 50,000$ scale, with $92.7 \%$ of the assessment points presenting errors of up to $15 \mathrm{~m}$, with standard deviation of $8.6 \mathrm{~m}$. Using the scenes with processing level L1B with ENVI /ASTERDTM, without any ground control point, the specification for a class C for 1:50,000 scale is reached, with $96.3 \%$ of the 41 assessment points presenting errors of up to $15 \mathrm{~m}$, with a standard deviation of $6.1 \mathrm{~m}$.

These results ensued a questioning to the PCI representative in Brazil, with forwarding of all the data used, being answered by PCI that there was no failure or problem. It is therefore understood that the ASTERDTM modeling - which is a specialized ASTER module - is more appropriate.

\subsection{ALOS/AVNIR-2: Planimetric assessment of orthoimage}

The ALOS/AVNIR-2 data, as well as those of the PRISM sensor of the same satellite, are of great interest for Brazil, since its data was distributed by IBGE (Instituto Brasileiro de Geografia e Estatística) for noncommercial users at a much lower price than those practiced by the market for products with the same features. It remained to know its accuracy in order to be able to fully explore its real capacity. The AVNIR-2 sensor acquired data in 4 spectral bands (blue, green, red and near infrared) with a spatial resolution of $10 \mathrm{~m}$. Since the satellite contained a very advanced set of orbital and altitude control systems, its use would be very appropriate both for reference as for thematic cartography.

The results presented here refer to the work published by a group of IBGE employees in [19] who assessed the orthoimage geometry of this sensor.

Orthoimage was generated in Orthoengine 10.2, by PCI, with a resolution of $10 \mathrm{~m}$, based on a scene acquired with processing level 1B2R, making use of seven ground control points and DEM SRTM version 4.0. The control points and the 34 assessment points were obtained from orthoimages in scale 1:25,000 generated by IBGE from photos in the scale 1:35,000. This 
study area covered the cities of Uberlândia, Indianópolis and Araguari, state of Minas Gerais, in Southeast Brazil. The topography of this area is less mountainous with height differences not exceeding $400 \mathrm{~m}$.

The results indicate that the orthoimage presents a planimetric accuracy equivalent to the class A of scale 1:50,000, since $90 \%$ of the assessment points presented errors of up to $21.7 \mathrm{~m}$ (already including the external error of the orthophotos - of up to $12.5 \mathrm{~m}$ ), with standard deviation of $3 \mathrm{~m}$. The authors of the referred work emphasize that the assessment only focused on geometry, like the remaining assessments here presented.

\subsection{Landsat 7 ETM+: Planimetric assessment of the orthoimage}

This assessment was the first research on the geometric accuracy of remote sensors carried out in 2004, by Laboratory ESPAÇO, with the specific purpose to obtain the planimetric accuracy of the Landsat images when orthorectified using the SRTM DEM (a novelty at that time). Despite being a quite well-known sensor, we consider its inclusion in this chapter appropriate for historical reasons and for its resemblance with the TM images from Landsat 5. Presently (2012) Brazil is concluding the updating of reference maps in the scale 1:250,000 using TM sensor images as main input.

Orthoimage was produced from the band 3 (red) of a scene (Path/Row 218/076) of sensor ETM+ (Enhanced Thematic Mapper Plus), Landsat 7 satellite, acquired in August 1999, with processing level 1G. Orthorectification was made with Orthoengine 9.0, by PCI Geomatics, using 10 ground control points (GCPs) - whose coordinates were determined by a navigation GPS (C/A - Coarse Acquisition Code) - and SRTM DEM version 1 (90 m pixel). The choice for the navigation GPS was due to the ETM plus image characteristics - $30 \mathrm{~m}$ pixel - and the lack of availability of single or double frequency trackers at that time.

In the planimetric accuracy assessment of orthoimage from Landsat 7 ETM+ only 4 assessment points were used, with coordinates determined by relative static positioning, through single frequency GNSS receivers. It was chosen to work with a small number of points for the assessment, but to determine their coordinates with greater accuracy.

The study area corresponds to the part of the municipality of Angra dos Reis, in Rio de Janeiro, Southeast Brazil. Relief is mountainous in most of the scene, with height differences over 1,000 m, for being part of the Serra do Mar Range. The prevailing vegetable cover consists of tropical forests, with presence of grasses/pastures in some areas.

It was observed that the 4 assessment points presented positioning errors of up to $70 \mathrm{~m}$ with an $\mathrm{SD}$ of $13 \mathrm{~m}$. The results obtained suggest that the orthoimage presents a planimetric accuracy compatible with the specification for a class B for 1:100,00 scale.

\subsection{SPOT 4: Planimetric assessment of the orthoimage}

Likewise as in the assessment of the Landsat Orthoimage, this was one of our first planimetric accuracy assessments. The SPOT 4 images were renowned as having a very 
good geometry and it was habitual to use the panchromatic band of that sensor (HRVIR) in scales 1:25.000 and 1:50.000.

The orthorectification of the panchromatic band (in fact it covers the red band -0.61 to $0.68 \mu \mathrm{m}$ ), with a $10 \mathrm{~m}$ spatial resolution, was carried out with Orthoengine 9.0, by PCI Geomatics, using 7 GCPs and SRTM DEM.

The assessment used 7 points, whose coordinates were determined by relative static positioning (likewise as for the GCPs), with single frequency GNSS trackers.

The study area was also the same used in the assessment of the Landsat Orthoimage and corresponds to part of the municipality of Angra dos Reis, Rio de Janeiro, Southeast Brazil.

The results suggest that the Orthoimage presents an accuracy compatible with the Class A for 1:50,000 scale or Class $C$ for 1:25.000 scale, since all points presented errors up to $20.5 \mathrm{~m}$ and SD of 7.4 metros. Likewise as in the Landsat assessment, the use of a small amount of points in the assessment does not allow to surely warrant the accuracy, but it is an indicator of its quality in terms of geometry.

Finalizing this part of the chapter, we present a summary table (table 3) with results from the accuracy assessments in terms of geometry for each of the sensor products analyzed:

\begin{tabular}{|c|c|c|c|}
\hline Sensor & Product & Scale & Classe/PEC \\
\hline \multirow{2}{*}{ LIDAR } & Orthophoto & $1: 2.000$ & Class A \\
\cline { 2 - 4 } & MDT & $1: 2.000$ & Class B \\
\cline { 2 - 4 } & MDS & $1: 5.000$ & Class C \\
\hline \multirow{2}{*}{ Geoeye-1 } & Orthoimage & $1: 2.000$ & Class B \\
\cline { 2 - 4 } & DEM & $1: 10.000$ & Class C \\
\hline \multirow{2}{*}{ IKONOS-2 } & Orthoimage & $1: 2.000$ & Class C \\
\cline { 2 - 4 } & DEM & $1: 10.000$ & Class C \\
\hline \multirow{2}{*}{ CARTOSAT-1 } & Orthoimage & $1: 10.000$ & Class B \\
\cline { 2 - 4 } & DEM & $1: 25.000$ & Class A \\
\hline \multirow{2}{*}{ ALOS / PRISM } & Orthoimage & $1: 25.000$ & Class A \\
\cline { 2 - 4 } & DEM & $1: 25.000$ & Class A \\
\hline ALOS / AVNIR & Orthoimage & $1: 50.000$ & Class A \\
\hline \multirow{2}{*}{ ASTER / VNIR } & Orthoimage & $1: 50.000$ & Class B \\
\cline { 2 - 4 } & DEM & $1: 50.000$ & Class C \\
\hline \multirow{2}{*}{ SRTM (DEM) } & Version 1 & $1: 50.000$ & Class C \\
\cline { 2 - 4 } & Version 2 & $1: 50.000$ & Class C \\
\cline { 2 - 4 } & Version 4 & $1: 50.000$ & Class C \\
\cline { 2 - 4 } & Topodata & $1: 100.000$ & Class A \\
\hline SPOT 4 / HRVIR: Pan & Orthoimage & $1: 50.000$ & Class A \\
\hline Landsat 7 / ETM+ / Multiespectral Band & Orthoimage & $1: 100.000$ & Class B \\
\hline
\end{tabular}

Table 3. Summary results of the assessments 


\section{Issues (still) remaining: Some limitations persisting and potentialities observed}

Besides being somewhat limited, the evaluations using PEC made sense for analog mapping, whose construction processes were more vulnerable to graphic issues, such as the tracing of the elements properly. Considering altimetry, it becomes even less valid for the digital data, because reference is made to the contour lines interval, without mentioning specific scales. In several applications, nowadays, it is possible to have a DTM or DEM and, based on them, automatically extract the contour lines, in case required. But what matters is that the primary product tends to be the digital model and not the contour lines, which are dispensable for most of the applications, except in the case when it is desired to print the base with the altimetry represented in a way to allow quantitative estimates. According to this reasoning, it is necessary to assess the accuracy of the DTM or DEM, because they normally are inputs from derived products, although the official Brazilian norm does not make any reference to this type of product. Obviously one should maintain the assessment of the contour lines in the cases where they represent the altimetry.

Even considering the PEC as reference, it can only be applied for assessment of the geometry of reference cartography products. There is no official norm for assessment/evaluation of thematic cartography products in Brazil. Therefore, thematic mappings present accuracies - both in terms of geometry as contents - which are either not assessed or which remain to be decided by the specifications of their producers. The importance of the establishment of norms is emphasized once more, or, at least the establishment of national standards that facilitate data interchange with levels of accuracy that can be known and compared. Brazil is presently making an endeavor to divulge its National Spatial Data Infrastructure (INDE), expanding the utilization of geospatial data in an appropriate manner. Such an endeavor also focuses on the adoption and dissemination for the use/generation of metadata. In this context, the knowledge of the accuracy of the products, whether referential or thematic, is mandatory.

It is clear that both for the reference cartography as for the thematic cartography the assessment should not be restricted to the accuracy of the geometry, but should consider also the reliability of what is being represented - i.e., its actual contents. In this context, some items to be considered are: what is represented, the amount of elements presented, the taxonomic level reached, the level of detail, etc. Obviously, for reference cartography some elements may have greater relevance while in the thematic cartography others may deserve more attention. It is necessary to disseminate among the users and producers of cartographic data the importance to know the quality, both of the geometry as the contents, the detailing of the mapping, always assessed considering the scale adopted. Despite seeming obvious, it is quite common to find the distribution of products presented as compatible with a certain scale, but in the assessment made, one finds that the concern was merely with the accuracy for geolocation, i.e., with the geometry. Among the non-specialist users the problem is even greater, because they rely more easily on the information provided and end up acquiring products which do not correspond to their needs and, when 
trying to extract an amount of information proportional to the desired scale, they perceive that it is impossible. In some of these cases the user may reach the conclusion that the maximum scale that can be reached for the product in terms of geometry can be very different from the maximum scale reached in terms of information contents available in that product. However, in other cases it is also possible that the user does not even perceive such difference and will end up making inappropriate use of that data.

The authors have no intention to criticize the performance of assessments regarding only accuracy. Actually, what we have been doing mostly, in a systematic way, is this type of assessment. The interest lies in calling attention for the need to complement the assessments with considerations regarding accuracy of the represented contents. As the existence of a critical mass regarding the need for assessments for accuracy of geometry is already perceived, it is desired to create a demand for investigations regarding the contents of what is represented.

As an example of such duality in the assessment of accuracy for the case of orbital images, we can mention the ALOS/PRISM in [16] planialtimetric data assessment report and in [19] on planimetric assessment of AVNIR2 images. Both texts present the maximum scales in terms of planialtimetric and planimetric accuracy, respectively, mentioning that the products may not allow the extraction of elements in the same scale. In order to know this last information it would be necessary to carry out an assessment of the images interpretability.

It is also important, to minimize the intensity of a statement - which is sometimes mentioned - that for thematic cartography, geometry may be neglected, while for reference cartography geometry is all that matters. Due to this, many thematic maps present serious geometry problems, which makes them incompatible for the foreseen scale, likewise as in reference cartography one may find maps - often adjacent to each other - that present different information densities, or even, a lack of standardization of what is being represented.

It is necessary to think about the problem, to suggest solutions and create a form of assessment that is really viable for the use by several producers of cartographic data whether referential or thematic, whether originated from official mapping agencies or private companies, research groups, etc. who handle these types of data. What matters is to invest in the proposition of standards for assessment of such data. These standards should be appropriate for the new techniques for data acquisition and handling, considering the digital context and dealing with accuracy in terms of geometry and contents.

When we consider the use of remote sensing data - whether originated from aerial or orbital levels - a set of cares is necessary, starting with the appropriate sensor choice, the time of the year for data acquisition, but treatment of the data and extraction of the desired information.

People often say that the only optimal solution is the one obtained through photogrammetric survey. And for many applications it really is the best. But a survey carried out in the scale and dates desired is not always available. And for other applications 
the optimum solution may be a survey carried out by radar. Other times we find people who do not even think of using photographs, because beforehand they state that the solution is through the use of orbital data. But it may happen that in this type of survey you may not get the acquired image with the geometry and/or level of detailing most appropriate for your application. In other words, the choice of the sensor should be made by an evaluation comparing costs and benefits, focused on the application. Each option normally presents benefits and drawbacks which should be evaluated case-by-case.

Since the appearance and dissemination of high resolution (spatial) sensors, they became the source of the most desired images for several applications that work with medium to large scales. However, not always the spatial resolution is what matters. For several thematic applications, such as mapping of vegetation or land coverage and land use, the spectral resolution is a factor equally or more important than the spatial resolution. On the other hand, one problem which is often overlooked in the planning is the time that it may take to acquire an image (or pair of images) for a certain location. Even with sensors presenting a small revisiting period, for meteorological issues or for great data demand, months may pass until the data is effectively acquired, even if paying a priority rate. For several applications this may be a limiting factor.

There are other basic issues that are sometimes neglected: when choosing to pay an expressive amount for high spatial resolution images, it is assumed that the application is for scales that need greater detailing which, at their turn, demand also greater accuracy in terms of geometry. However it is not rare to find users who acquire such data and do not make the appropriate geometric modeling/correction - the orthorectification, with RPCs supplied by the satellite owner, GCPs (ground control points) with compatible accuracy and appropriate DEM. Even images with good internal geometry will present relatively high external errors if they are not well modeled, especially in areas with great attitude differences. And this is not acceptable in the immense majority of applications that effectively require data with great detailing.

Users of images that allow a more regional coverage - sensors normally included in the category of medium spatial resolution - should be feeling more difficulty to update data since Landsat 5 presented problems in November 2011 in [20], since there is practically no alternative that offers the same possibilities (especially considering cost and data availability). Environmental studies have a great demand for data of this category and need to search for alternatives, as the use of sensors of greater spatial resolution, normally losing spectral resolution - with highlight for the lack of availability of the SWIR band - in most of those sensors.

While the producers of thematic data are experiencing a certain period of low availability of these sensors of medium spatial resolution and highest spectral resolution, the opposite has been occurring for producers of reference cartographic data. These sensors of medium to high spatial resolution (between 2.5 and 5 meters), high (between 1 and 2.5 metros) and very high (below $1 \mathrm{~m}$ ) can rely on a great offer of inputs. New sensors with higher spatial resolutions are becoming available almost every year. In Brazil, as mentioned before, 
photogrammetric flights for systematic cartography are again being contracted in greater quantity, making more data aimed at greater scales available (mainly 1:25,000 or above), in addition to a growing offer of LIDAR and RADAR data. Regarding this latter sensor - the project "Amazon Radiography" is presently ongoing, with the use of airborne interferometer RADAR, in the $\mathrm{X}$ and $\mathrm{P}$ bands, for production of a cartographic reference base in scale 1:50,000 and 1:100,000, among other products in [21].

One feature that may soon become more common for orbital sensors is the planning of Earth observation missions that count with a constellation of satellites as for instance, Rapideye. Obviously, besides technical issues, the constellations tend to favor the reduction of interval revisits, increasing the chance of success in the acquisition of data in the area desired.

Another important remark is the appearance of new spectral bands of high spatial resolution, such as the coastal, yellow and red edge, which offer new investigation possibilities for the enhancement of thematic maps.

With increasingly better orbital and attitude control systems, image suppliers have been offering products with geolocation which are increasingly accurate, at least in areas with flat topography. In some cases those images may even dispense the need for geometric correction for users who work in scales which do not demand great accuracy. Orthorectified images can even be acquired for some products, without the need for the user to supply ground control points.

The possibilities seem endless, with new offers of data and applications arising constantly. However, a critical eye should be kept on each input or product, in order to know their real potentialities and limitations.

\section{Conclusion}

With the systematic offer of new and re-paged sensors, it is increasingly difficult to close a discussion on the subject. It is a fact that Remote Sensing is becoming indispensable for many cartographic applications, for all its already mentioned facilities. With all this, in the present phase, it is extremely important that the investments for assessment of so many products offered are made, in order to direct them to a conscious use, with awareness of the problems involved, thus avoiding loss of time and resources. The existent shift from analog to digital paradigm is also emphasized, which becomes an additional requirement in the reassessment of methods and processes, not only of products.

Still regarding the new sensors, one may state that the present scarcity of sensors of medium resolution has become a serious problem in mapping and monitoring of natural phenomena and events, mainly in countries with great territorial extensions such as Brazil. It is fundamental and urgent that investments be made in the sector. On the other hand, we emphasize our present concern with the maintenance and the investments in remote sensors that seek to meet the requirements of global studies (low resolution and great coverage), as in the case of climate changes, and local studies (high resolution), as for instance sensitivity and risk maps in support of natural disasters. 
It is interesting that we are quickly reaching the point of discussing ethical and legal issues, such as the new limitations for the progress of orbital imaging at still greater detail levels, which reflect problems such as invasion of privacy and national security.

In the case of Brazil, as in any other country, there is a choice of sensors which for several reasons become interesting, and which naturally prevail over the remaining, responding for the great majority of applications. In this investigation, we seek to focus those cases, trying to contribute for greater clarification regarding the potential and limitations of each option, limiting ourselves in this first approach to geometric issues. The 10 sensors presented here constitute the first phase of our investigation line, which will have continuity in the assessment of new sensors, such as Rapideye, Terrasar- $X$ and Worldview 2. Another effort that is being developed, but which is still in an initial phase, is the diligent assessment of the potential of those products for extraction of the cartographic elements, a term which we call interpretability, whose scale of attendance tends to be less than the one defined by geometry.

The organization of the assessments carried out in three classes of scales was considered important for a better orientation of applications by the users. The limits adopted, using as important threshold the 1:25,000 scale, represent mapping challenges in Brazil, whose scarcity at this level of detail is immense. Considering the country's growth, the demand for reliable georeferenced information has increased a lot, which may translate a greater concern for its attendance by specialized institutions of the sector and, on the other hand, unfortunately, the explosion of individualized, and standalone solutions, in most cases, without the necessary control and knowledge. It is sought therefore, to contribute for the awareness of the community in general regarding those issues.

\section{Author details}

Carla Bernadete Madureira Cruz and Rafael Silva de Barros

Departamento de Geografia, Instituto de Geociências, Universidade Federal do Rio de Janeiro - UFRJ, Rua Athos da Silveira Ramos, CCMN, Cidade Universitária, CEP 21941-590 - Rio de Janeiro, Brasil

\section{Acknowledgement}

Our thanks to the Research Center Leopoldo Americo Miguez de Mello (CENPES), Petrobras, which supported this research by providing the resources necessary for its preparation.

\section{References}

\section{Journal}

[8] TOUTIN, T. \& CHENG, P. (2002) Comparision of Automated Digital Elevation Model Extraction Results Using Along-Track ASTER and Across-Track SPOT Stereo Images. SPIE Journal, Optical Engeneering, 41 (9), p. 2102-2106. 
[9] TOUTIN, T. (2004) Comparison of Stereo-Extracted DTM from Different High-Resolution Sensors: SPOT-5, EROS-A, IKONOS-II, and QuickBird. IEEE Transactions on Geoscience and Remote Sensing. 42(10):2121-2129.

\section{Online journal}

[1] INPE. Notícias. (2010) Site: http://www.inpe.br/noticias/noticia.php?Cod_Noticia=2148. Último acesso 29/03/2012.

[2] GOOGLE. Google History. (2012) Site: http://www.google.com/about/company/history. html\#2005. Último acesso 29/03/2012.

[14] BRASIL, Decreto 89.817 de 20 de junho de 1984. (1984) Estabelece as Instruções Reguladoras das Normas Técnicas da Cartografia nacional. Diário Oficial da República Federativa do Brasil, Brasília, n120, 22 de junho de 1984. Site: http://www.planalto.gov.br/ccivil_03/decreto/1980-1989/D89817.htm. Último acesso: 10 de abril de 2012.

[16] IBGE. Avaliação Planialtimétrica de Dados ALOS/PRISM Estudo de Caso: Itaguaí - RJ. (2009) Disponível em http://www.ibge.gov.br/alos/RelatoriodeAvaliacaoAlos.pdf. Último acesso: setembro 2009.

[20] NASA. (2012) Landsat 5. Site: http://landsat.gsfc.nasa.gov/about/landsat5.html. Último acesso: 10 de abril de 2012.

\section{Theses}

[3] FERNANDES, M. C. (2004) Desenvolvimento de Rotina de Obtenção de Observações em Superfície Real: uma aplicação em Análises Geoecológicas. Tese de Doutorado. IGEO / UFRJ.

[4] VICENS, R. S. (2003) Abordagem geoecológica aplicada `as bacias fluviais de tabuleiros costeiros no Norte de Espirito Santo: uma contribuição para avaliação e gestão de recursos hídricos. [Rio de Janeiro], 252p.(IGEO/ UFRJ), D.Sc., Geografia, Tese Universidade Federal do Rio de Janeiro, IGEO.

[5] GOMES, R. A. T. (2002) Modelagem de previsão de movimentos de massa a partir da combinação de modelos de escorregamentos e corridas de massa. [Rio de Janeiro], 102p.(IGEO/ UFRJ), D.Sc., Geografia, Tese - Universidade Federal do Rio de Janeiro, IGEO.

[6] GUIMARÃES, R. F. G. (2000) Utilização de um modelo de previsão de áreas susceptíveis à ocorrência de escorregamentos rasos com controle topográfico: adequação e calibração em duas bacias de drenagem. [Rio de Janeiro], (IGEO/ UFRJ), D.Sc., Geologia, Tese Universidade Federal do Rio de Janeiro, IGEO.

[7] CORREIA, J. D. (2008) Mapeamento de feições deposicionais quaternárias por imagens orbitais de alta resolução espacial - Médio Vale do Paraíba do Sul. Tese Doutorado, IGEO/UFRJ.

[11] SANTOS, P. R. A. (2005) Avaliação da Precisão Vertical dos Modelos SRTM em Diferentes Escalas: Um Estudo de Caso na Amazônia. Dissertação de Mestrado. IME. Rio de Janeiro. 
[12] BARROS, R. S. (2006) Avaliação da Altimetria de Modelos Digitais de Elevação Obtidos a Partir de Sensores Orbitais. [Rio de Janeiro], 2006 XIX, 172p.(IGEO/ UFRJ), D.Sc., Geografia, Tese - Universidade Federal do Rio de Janeiro, IGEO.

[13] CRUZ, C. B. M. (2000) As bases operacionais para a modelagem e implementação de um banco de dados geográfico - um exemplo aplicado à bacia de Campos, RJ. [Rio de Janeiro], IGEO/ UFRJ), D.Sc., Geografia, Tese - Universidade Federal do Rio de Janeiro, IGEO.

\section{Annals}

[10] GONÇALVES, G. A.; da SILVA, C. R.; MITISHITA, E. A. (2005) Comparação dos Dados do SRTM com as RNs da Rede Geodésica Altimétrica do IBGE para Região Sul do Brasil. In: IV Colóquio Brasileiro de Ciências Geodésicas. Curitiba - PR.

[15] SANTOS, S. D. R.; HUINCA, S. C. M.; MELO, L. F. S.; SILVA, M. T. Q. S.; DELAZAR, L. S. (2010) Considerações sobre d Utilização do PEC (Padrão De Exatidão Cartográfica) Nos Dias Atuais. In: III Simpósio Brasileiro de Ciências Geodésicas e Tecnologias da Geoinformação. Recife - PE, 27-30 de Julho de 2010. p. 1-5.

[17] BARROS, R. S.; COELHO, A. L.; OLIVEIRA, L. F.; MELO, M. F.; CORREIA, J. D. (2009) Avaliação Geométrica de Imagens ALOS/PRISM níveis 1B2G e 1B2R ortorretificada estudo de caso: Itaguaí-RJ. In: XIV Simpósio Brasileiro de Sensoriamento Remoto. Florianópolis.

[18] VALERIANO, M. M. (2005) Modelo digital de variáveis morfométricas com dados SRTM para o território nacional: o projeto TOPODATA. In: XII Simpósio Brasileiro de Sensoriamento Remoto, 2005, Goiânia, GO. Anais do XII Simpósio Brasileiro de Sensoriamento Remoto. p. 1-8.

[19] BARROS, R. S.; COELHO, A. L.; MELO, M. F.; CORREIA, J. D.; OLIVEIRA, L. F. (2010) Avaliação Planimétrica de Dados ALOS/AVNIR-2. Estudo de caso: Uberlândia - MG. In Congresso Brasileiro de Cartografia. Sergipe.

[21] CORREIA, A. H. (2011) Metodologias e Resultados Preliminares do Projeto Radiografia da Amazônia. In: XV Simpósio Brasileiro de Sensoriamento Remoto. Curitiba. Brasil. 